\title{
Benign Epiglottis Neoplasm
}

National Cancer Institute

\section{Source}

National Cancer Institute. Benign Epiglottis Neoplasm. NCI Thesaurus. Code C4606.

A non-metastasizing neoplasm that arises from the epiglottis. 